\title{
Evaluation of Different Enamel Reconditioning Techniques for Effective Orthodontic Bracket Rebonding
}

\author{
Amal M Fadl El-kareem ${ }^{1}$, Saleh S Anwar ${ }^{1}$, Wessam G. Raafat *1 ,Hasan El-Fakahany²
}

Codex : 09/2021/04

Aadj@azhar.edu.eg

\section{KEYWORDS}

Fractional CO2 Laser,

Ultra Sonic scaler, Air abrasion,

Orthodontic Bracket Rebonding,

shear bond strength

1. Department of orthodontics, Faculty of dental medicine, (Assiut, boys ), Al-Azhar University, Egypt.

2. Department of dermatology and androgynous, Faculty of Medicine, Minia University, Egypt

* Corresponding Author e-mail: wesamgouda.el8.540@azhar.edu.eg

\begin{abstract}
Aim: Aims and objectives of the study were to measure shear bond strength of rebonded orthodontic brackets after using different enamel reconditioning techniques including (Diamond bur, Air abrasion with Aluminum Oxide particles, Ultra Sonic scaler, $\mathrm{CO}_{2}$ laser ).Subjects and methods : This in vitro study consists of five groups with ten samples in each group. Each sample was bonded with a metal bracket. After debonding, reconditioning of the tooth surface was performed by the finishing Diamond bur, Air abrasion, Ultra Sonic Scaler and Fractional $\mathrm{CO}_{2}$ Laser . Rebonding of the reconditioned teeth was again performed. Universal testing machine was used to evaluate the shear bond strength of the orthodontic brackets. Enamel surface topography was evaluated using scanning electron microscope. Results: The maximum average score of shear bond strength was in the LASER Group (16.4 Mega Pascal ) (MPa) followed by Ultra Sonic Scaler (16.2MPa), The Control Group (14.9MPa), Sand blasting Group (14.6MPa), at last the Diamond Burs group (11.3MPa). There was a relationship between surface roughness and the bond strength achieved. The method which created a smoother uniform surface achieved the higher shear bond strength. Conclusions: Fractional $\mathrm{CO}_{2}$ Laser, Ultra Sonic scaler and Air abrasion can be used as preferred method of reconditioning the tooth surface after bond failure instead of diamond burs to achieve optimal bond strength of rebonded brackets.
\end{abstract}

\section{INTRODUCTION}

Clinical efficiency and treatment duration in orthodontics can be compromised by bond failures. Some authors rank accidental bracket failure as one of the most important predictors of fixed appliance treatment duration. ${ }^{1}$.According to authors the shear bond strength should exceed the occlusal loading which may reach $1,5 \mathrm{~kg} / \mathrm{c} \cdot \mathrm{m}^{2} .{ }^{2,3}$. Rebonding the orthodontic brackets should provide a bond strength efficient for continued orthodontic treatment to facilitate rebonding the search for a safe and efficient method for rebonding attracted the attention of many researchers, which resulted in the introduction of numerous tools and techniques. ${ }^{4}$ These include the diamond cutting burs ${ }^{5}$, the Ultra Sonic 
scaler ${ }^{6,7}$ and the $\mathrm{AL}_{2} \mathrm{O}_{3}$ Sandblasting ${ }^{8,9}$ Studies have recommend different methods for an ideal adhesive removal technique which would minimize iatrogenic damage while returning the enamel to its pretreatment smoothness, and provide optimal bond strength for the orthodontic brackets rebonding. ${ }^{10,11}$. So this study have been conducted to measure shear bond strength of rebonded orthodontic brackets after using different enamel reconditioning techniques and suggesting the Fractional $\mathrm{CO}_{2}$ Laser as a new proposed method .Also evaluating the reconditioned enamel surface topography using Scanning Electron Microscope

\section{MATERIALS AND METHODS}

A sample of 50 first premolar teeth extracted for orthodontic purpose was used and selected on the following inclusion criteria, intact enamel, non carious,non restored and no enamel hypoplasia. The teeth collected were stored at room temperature in distilled water (Aqua Bure lab) (PH : 6,50-6,8) for 24 hour . All teeth were mounted on self-cured acrylic resin block in a way that root was embedded into the acrylic just below the cemento-enamel junction level leaving the crown fully exposed.

The buccal surfaces of all teeth were etched with 37\% Ortho-Phosphoric acid etching gel (Total etch, Ivoclar, Vivadent,Schaan, Liechtenstein) for $30 \mathrm{Sec}$, washing for $30 \mathrm{Sec}$ and dryness of the enamel surface . Thin layer of primer (Reliance ${ }^{\circledR}$ Light Bond, Reliance Orthodontic Product, Itasca, IL) was applied on enamel surface . A thin layer of primer was applied over bracket base (Ormco Mini $2000^{\circledR}$, Metal, Kerala, India), followed by a thin layer of adhesive (Reliance ${ }^{\circledR}$ Light Bond,Reliance Orthodontic Product, Itasca, IL .The bracket was mounted on the tooth with the help of direct bond bracket tweezer with light pressure, the excess composite was then removed by dental explorer . All the samples were light cured using (LED, Ivoclar Vivadent, Blue phase,Germany) for 30 seecond.
The samples were randomly divided into five groups of 10 samples each according to different adhesive removal methods which were as followed:

Group One: Control group Initial bonding followed by debonding and rebonding with no surface treatment done . (Figure1).

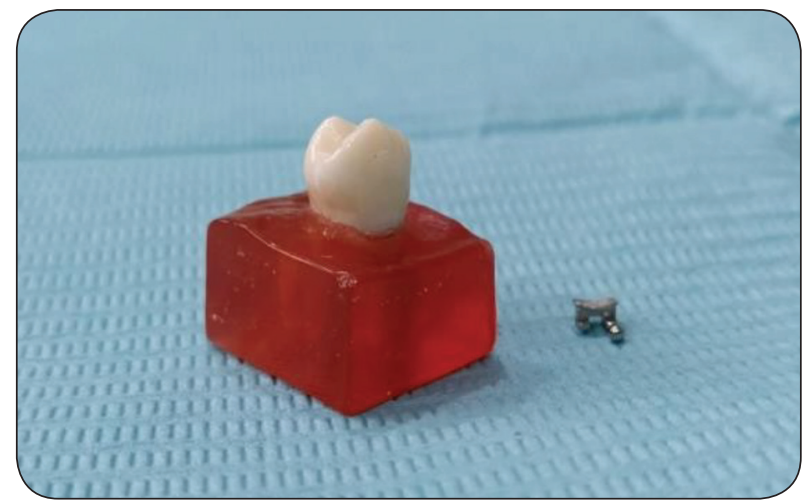

Fig. (1) Control group .

Group 2: Enamel surface reconditioning with diamond cutting bur (TF-11, ISO 173/014, SS White, USA) using High Speed Hand piece (Dentsply, Sirona,T3 Led hand piece, Triple water spray, 2 Holes, North Carolina, USA 35000-40000 rpm) with air cooling and gentle pressure. (Figure2).

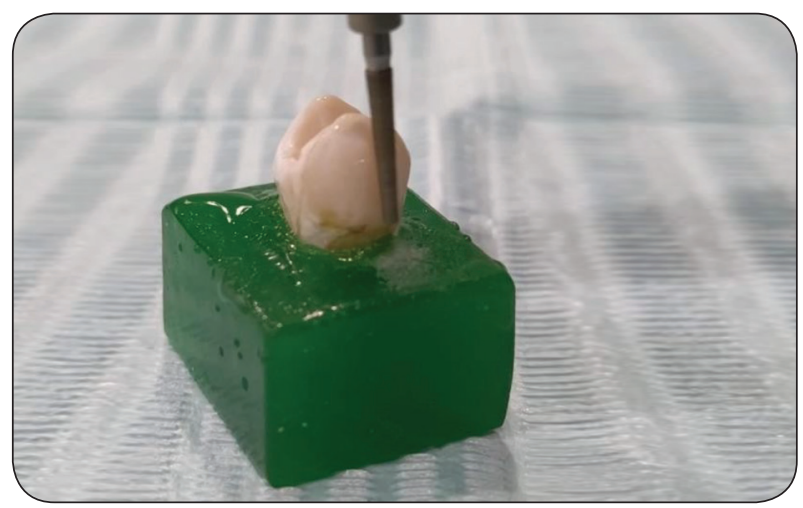

Fig. (2) Diamond cutting burs group.

Group 3: Enamel surface reconditioned using Ultra Sonic Scaler (Woodypecker UDS-A LED,China, G5 tip), under water cooling. (Figure3)

Group 4: Enamel surface reconditioning with Plastic Airflow Prophy Jet Cavitron (Yearsun, Air pressure 0.3Mpa-0.4Mpa, Guangdong, China),Jhonson Promident, Aluminum Oxide 
Powder (50 Micron, White, 2Lb, 505050, Valley Cottage, NY). The teeth surfaces were held $5 \mathrm{~mm}$ away from the nozzle of micro etcher. (Figure4).

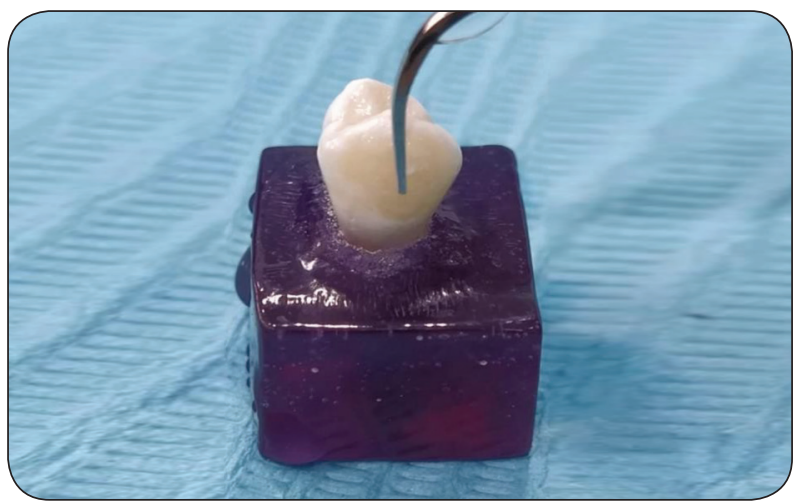

Fig. (3) Ultra sonic scaler treatment.

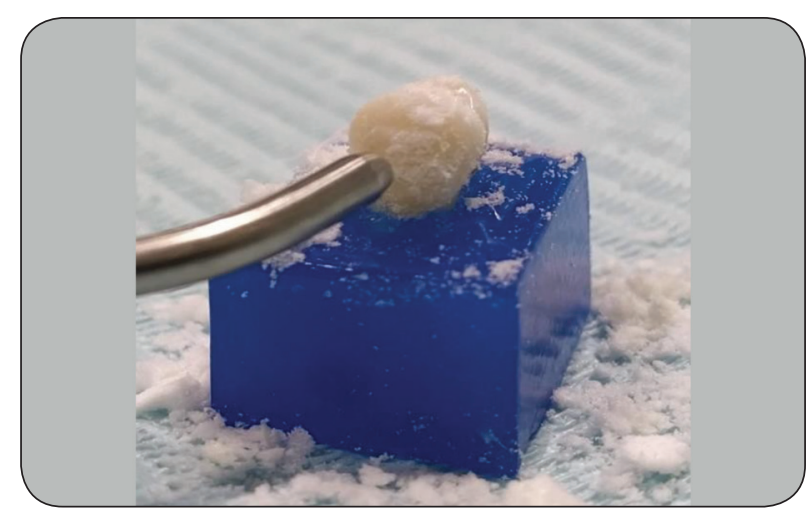

Fig. (4) $\mathrm{Al}_{2} \mathrm{O}_{3}$ Sandblasting

Group 5: Enamel surface reconditioning using Fractional $\mathrm{CO}_{2}$ laser Device (ECOXEL, IDS, Fractionl $\mathrm{CO}_{2}$ laser, Laser power 1-40W, Seoul, Korea). IOS Laser Technologies, was irradiated to the enamel surface with the $5 \mathrm{~Hz}$ Frequency, $10.6 \mu \mathrm{m}$ wavelength, $3 \mathrm{~W}$ output power, 0.9 seconds pulse time by an experienced operator with a uniform fractions with a number of 10 pulses totally. (Figure5).

For all the groups, debonding was carried out with the Universal Testing Machine at the crosshead speed of $5 \mathrm{~mm} / \mathrm{min}$ to register the initial shear bond strength.The remaining composite was then removed using the proposed different technique .Rebonding was again carried out of the reconditioned tooth surface using a new bracket with the same method as stated earlier and then debonding was carried out with the Universal Testing Machine for measuring the shear bond strength for the rebonded brackets.

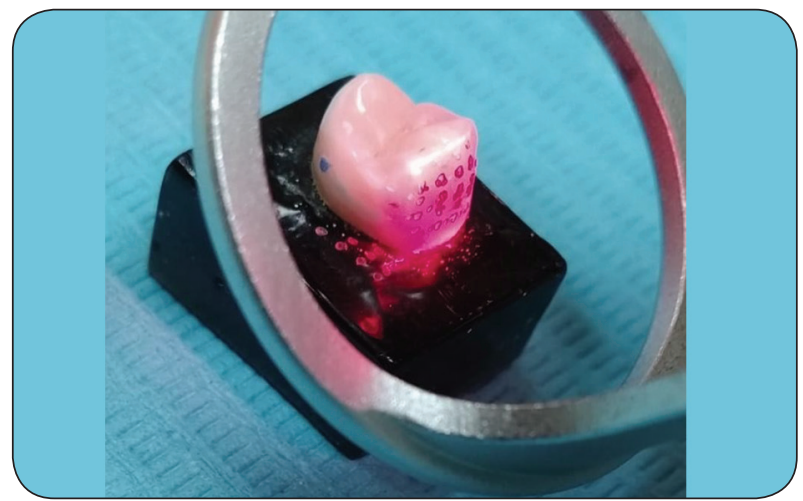

Fig. (5) $\mathrm{CO}_{2}$ Laser treatment

\section{Scanning Electron Microscopy (SEM) Evaluation for Enamel Surface Alteration}

One of the experimental group samples was checked for enamel surface alteration before any treatment to the enamel, after enamel etching, after first bracket debonding and after each enamel reconditioning technique with the scanning electron microscope. From each group, tooth with average bond strength was selected for SEM. For the standardization procedure, all the microphotographs were viewed under $35 \mathrm{X}$ magnification.

\section{RESULTS}

The maximum average score of bond strength was in the LASER Group (16.4MPa) followed by Ultra-Sonic Scaler (16.2MPa),The Control Group(14.9MPa), Sand blasting Group (14.6MPa), at last the Diamond Burs group (11.3MPa).Shear bond strength showed a significant difference in between different groups. (Taple 1).

SEM microphotographs revealed that more roughness of enamel surface was seen in the Diamond bur group (Group 2 ) which represented score (4) according to the modified surface roughness index originally proposed by Howell and Weekes, followed by, The Ultrasonic scaler group (Group3) with score (3) which showed cracks in the surface resulted from the scaler tip vibration 
The sand blasting group (Group 4) was given a score (2) for which showed mildly rough surface filled with parts of Alumina dispersed along the tooth surface .The control group (Group1) showed distinctive marks of the bracket base impression un distorted making the surface mildly rough giving it score(2), The Laser group (Group5) showed smooth surface at the areas of laser beams of both composite and enamel giving it score (1). (Table 2, Figure 6).

Table (1) Comparison of the shear bond strength results of all groups ranked form higher to lower.

\begin{tabular}{|l|c|c|}
\hline & Mean & ANOVE P Vlaue \\
\hline 1- Group (5) $\mathrm{CO}_{2}$ laser & 16.4 & \\
\hline 2- Group (3) U.S scaler & 16.2 & \\
\hline 3- Group (1) control & 14.9 & \multirow{2}{*}{$<0.001^{*}$} \\
\hline 4- Group (4) $\mathrm{AL}_{2} \mathrm{O}_{3}$ & 14.6 & \\
\hline 5- Group (2) cutting burs & 11.3 & \\
\hline
\end{tabular}

Table (2): The surface roughness of the samples ranked from high to low score according to Howell and Weeks.

\begin{tabular}{|l|l|}
\hline \multicolumn{1}{|c|}{ Groups } & Score \\
\hline Group (2) Cutting bur & Score 4 \\
\hline Group (3) Ultrasonic scaler & Score 3 \\
\hline Group (4) $\mathrm{AL}_{2} \mathrm{O}_{3}$ sandblasting & Score 2 \\
\hline Group (1) Control group & Score 2 \\
\hline Group (5) $\mathrm{CO}_{2}$ Laser & Score 1 \\
\hline
\end{tabular}


Previous studies compared between two different types of enamel reconditioning techniques like the cutting bur and the ultra sonic scaler which was conducted by Hossien et al. and Ireland et al. ${ }^{15}$

In this study we compared between 5 different enamel reconditioning techniques, the acid etch alone, the diamond cutting burs, the ultra sonic scaler, the $\mathrm{AL}_{2} \mathrm{O}_{3}$ Sand blasting powders and Fractional $\mathrm{CO}_{2}$ Laser as a proposed new technique .

In this study we used Reliance ${ }^{\circledR}$ orthodontic light bond as the bonding agent in both bonding and rebonding process, the initial shear bond strength recorded a value of (14.9 $\mathrm{MPa})$ which was acceptable for the occlusal forces and was supported by multiple studies previously conducted comparing different types of orthodontic adhesive resins present in the markets now a days.$^{16}$ With the debate between whether the initial bonding should have higher shear bond strength or the rebonding should have the higher value of shear bond strength. Some studies have found that rebonding shear bond strength was lower than the initial bond strength, as the initial shear bond strength was (15 MP) and the shear bond strength in rebonding was (11.3 MP). ${ }^{74}$ While other studies have found the rebonding strength was higher than the initial bond strength and the shear bond strength may reach to $(16 \pm 1 \mathrm{MP}) .{ }^{17}$

In this study the shear bond strength in rebonding varied according to the type of surface reconditioning technique, some were higher than the initial bond strength, the initial SBS recorded a value of (14.9 MPa) while the laser rebonding group recorded a higher SBS value of $(16.2 \mathrm{MPa})$, while the $\mathrm{AL}_{2} \mathrm{O}_{3}$ sand blasting group shear bond strength was (14.6MPa) which supports the results of a previous study conducted by Bulut. ${ }^{18}$ This study supports Divya Joshi ${ }^{19}$ study comparing different type of adhesive removing techniques. The SBS in rebonding orthodontic bracket achieved after removal of the residual adhesive with diamond bur was less than the air abrasion group. And using the scanning electron microscope to view the enamel surfaces, the diamond group showed highly roughed enamel surface than the enamel sand blasted group, that opposes Bayram et al. ${ }^{20}$ study that concluded the SBS achieved after roughening the surface with diamond bur at a high speed under water cooling could be higher than the sandblasting when super course diamond bur is used. This study results shows higher shear bond strength of the U.S scaler group (16.2MPa) when compared to the initial shear bond strength (14.9 MPa), this supports the results of a study conducted by Alessandri . $\mathrm{G}^{21}$ to compare the SBS of orthodontic bracket after removal of the resin using U.S scaler, the SBS was higher when compared with the initial SBS. The SEM images in this study shows better surface roughness of the Ultra Sonic scaler group than the cutting burs group, that supports Michele Machado ${ }^{22}$ study that show the difference in the enamel surface after different conditioning technique, the US scaler tips produced low roughness scores, thereby microscopically showing better surface, while the tungsten drills causing more damage to enamel surface. In this study we used the $50 \mu \mathrm{m}$ Aluminum Oxide particles as a reconditioning to the surface which created a smooth surface ready for etching promoting the shear bond strength to be (14.6 MPa), These results supports a study conducted previously comparing different particles size $(25,50,90 \mu \mathrm{m})$ Aluminum Oxide particles stated that $50 \mu \mathrm{m}$ fine Alumina particle causes a smoother surface thereby causing less iatrogenic effect on the enamel and yet

an improvement in the shear bond strength was found..$^{23}$ This study supports the study conducted previously claiming that no improvement in bonding strength is obtained with sandblasting before etching. ${ }^{24,25}$ but opposes the in vitro comparative study on sandblasting prior to acid etching vs. acidetching only revealing improvement in the bond strength. ${ }^{26-28}$ In this study we used Fractional $\mathrm{CO}_{2}$ Laser instead of conventional $\mathrm{CO}_{2}$ technology as less damaging to the enamel surface which was supported by previous studies showed that $\mathrm{CO}_{2}$ Laser energy can cut and burn composite resins to differing degrees and that Fractional $\mathrm{CO}_{2}$ Laser reduce the side effects with conventional $\mathrm{CO}_{2}$ and Er:YAG lasers. ${ }^{29}$ In this study we used $3 \mathrm{~W}$ 
power which was suggested in a study conducted by Smith.L,Walsh and Taverne. A. ${ }^{30}$ using $\mathrm{CO}_{2}$ Laser with different power setting 2,3,4 Watt for removing residue of orthodontic adhesive bonding resin from teeth, it showed that the $3 \mathrm{~W}$ is optimal for resin removal, and produces less enamel damage than other laser parameters. In this study the shear bond strength of the $\mathrm{CO}_{2}$ group was significantly higher that supports the study conducted previously to determine the $\mathrm{CO}_{2}$ laser effect on enamel surface alternation and its effect on bond strength . And this was attributed to the nature of the $\mathrm{CO}_{2}$ laser energy is well absorbed by the enamel causing physical and chemical changes on the enamel surface leading to enhancement in the shear bond strength. ${ }^{31}$ The results in this study supports Oshagh et al. ${ }^{32}$ results when compared the SBS of orthodontic brackets in bonding and rebonding with teeth using $\mathrm{CO}_{2}$ laser versus conventional acid etching technique. The authors concluded that the primary preparation with acid had a higher mean SBS $(10.3 \pm 5.5 \mathrm{MPa})$ compared to that of $\mathrm{CO}_{2}$ laser alone, SBS was $(10 \pm 2 \mathrm{Mpa})$. Secondary preparation of the enamel using $\mathrm{CO}_{2}$ laser and acid etch showed the highest mean SBS value than the primary preparation with laser and the SBS was $(13 \pm 3 \mathrm{MPa})$, the results suggested the use of laser as a reconditioning technique in rebonding of brackets.

In this study,the SBS for all the tested groups appeared to be clinically acceptable, implying that all the used enamel reconditioning techniques can be used for the orthodontic rebonding procedures.

Future studies regarding the Fractional $\mathrm{CO}_{2}$ laser should be completed to further understanding of it is effect on enamel.

Forthcoming studies would benefit to determine the effect of both bonding and rebonding over the enamel surface and each of the enamel reconditioning technique and it is effect on long term orthodontic treatment. With the development of the Scanning Electron Microscope technology, more accurate data would be obtained for the enamel surface that could be of a great benefit for future studies of this kind.

\section{CONCLUSION}

The Diamond cutting bur group was significantly less in the shear bond strength value and more damaging to the enamel.

The Ultra Sonic Scaler achieved good results regarding to both the shear bond strength testing and enamel damage and it is better to use it instead of the Sandblasting technique.

Fractional $\mathrm{CO}_{2}$ Laser is advocated to be used as an enamel reconditioning technique as it lead to superior shear bond strength results compared to the other groups and the enamel damage was minor.

\section{REFERENCES}

1. Popowich K, Nebbe B, Heo G, Glover K, Major P. Predictors for Class II treatment duration. Am J Orthod Dentofacial Orthop .2005;127:293-300.

2. Sawsan A, Alomari, Elham S, Abu Alhaija. Occlusal bite force changes during 6 months of orthodontic treatment with fixed appliances. Aust. Orthod. J. 2012;28:197- 203.

3. Varga S, Spalj S, Milosevic S, Varga M, Mestrovic S, Zrinski M. Changes of bite force and occlusal contacts in the retention phase of orthodontic treatment: A controlled clinical trial. Am. J. Orthod. Dentofacial Orthop. 2017;152:767-77.

4. Tavares S. In vitro analysis of different methods of residual resin removal from tooth enamel. Dental Press J Orthod. 2011;16:146-54.

5. Aksu M and Kocadereli I.Influence of two different bracket base cleaning procedures on shear bond strength reliability. Journal of Contemporary Dental Practice . 2013;14:250-4.

6. Vyas N, Pecheva E, Dehghani H. High speed imaging of cavitation around dental ultrasonic scaler tips . PLoS ONE. 2016;11:14.

7. Lea B, Felver G, Landini and Walmsley A.Ultrasonic scaler probe oscillations and tooth surface defects. J. Dent. Res.2009 ;88:229-34.

8. Sara A, Alfadda B. Effect of Alumina Particle Size on the Bond Strength between Autopolymerized Acrylic Resin and Commercially Pure Titanium. J Prosthodont. 2019 ;28:466-70. 
9. Kilinc D, Sayar G. Comparison of the Shear Bond Strength of Treated and Untreated Brackets on Treated and Untreated Enamel Surfaces in Rebonding. J Orofac Sci.2018;10:69-74.

10. Hosein I, Sherriff M, Ireland A. Enamel loss during bonding, debonding, and cleanup with use of a self-etching primer. Am J Orthod Dentofacial Orthop. 2004;126:717-24.

11. Ireland A, Hosein I, Sherriff M. Enamel loss at bond-up, debond and clean- up following the use of a conventional light- cured composite and a resin-modified glass polyalkenoate cement. Eur J Orthod. 2005;27:413-9.

12. Ioannidis A, Papageorgiou S, Sifakakis I, Zinelis S, Eliades G, Eliade T. Orthodontic bonding and debonding induces structural changes but does not alter the mechanical properties of enamel. Prog Orthod. 2018;19:12.

13. Cal-Neto J, Miguel J. Scanning electron microscopy evaluation of the bonding

14. mechanism of self-etching primer on enamel. Angle Orthod. 2006;76:132-6.

15. Ireland A, Hosein I, Sherriff M. Enamel loss at bond-up, debond and clean- up following the use of a conventional light- cured composite and a resin-modified glass polyalkenoate cement. Eur J Orthod.2005;27:413-9.

16. Ireland A, Hosein I, Sherriff M. Enamel loss at bond-up, debond and clean- up following the use of a conventional light- cured composite and a resin-modified glass polyalkenoate cement. Eur J Orthod. 2005;27:413-9.

17. Sudhir S, Pradeep T, Amit N, Gyan P, Alka Sand .Chugh A. Comparison of shear bond strength of orthodontic brackets bonded with four different orthodontic adhesives. J Orthod .2016;115:133-228.

18. Eminkahyagil N, Arman A, Etins Ahin A, Karabulut E . Effect of resin- removal methods on enamel and shear bond strength of rebonded brackets. Angle Orthodontist. 2006 ;76:314-21.

19. Bulut A, Atsü S. The effect of repeated bonding on the shear bond strength of different resin cements to enamel and dentin. J Adv Prosthodont. 2017;9:57-66.

20. Joshi D, Singh K, Raghav P, Reddy M. Shear Bond Strength Evaluation of Rebonded Brackets Using Different Composite Removal Techniques. Int J Sci Stud. 2017;5:72-7.

21. Bayram M, Yesilyurt C, Kusgöz A, Ulker M, Nur M. Shear bond strength of orthodontic brackets to aged resin composite surfaces: Effect of surface conditioning. Eur J Orthod. 2011;33:174-9.
22. Alessandri G, Incerti S, Rita D, Gatto M, Checchi L. Effects of ultrasonic instrumentation with different scalertip angulations on the shear bond strength and bond failure mode of metallic orthodontic brackets. Korean Journal of Orthodontics, 2014;44:44-9.

23. Michele M, Rafael P, and Luciane H. Enamel surface evaluation after bracket debonding and different resin removal methods . Dental Press J Orthod . 2015:2:61-7.

24. Sara A, Alfadda B. Effect of Alumina Particle Size on the Bond Strength between Autopolymerized Acrylic Resin and Commercially Pure Titanium. J Prosthodont. 2019;28:466-70.

25. Brauchli L, Muscillo T, Steineck M, Wichelhaus A. Influence of enamel conditioning on the shear bond strength of different adhesives. J Orofac Orthop. 2010;71:411-20.

26. Robles-Ruız J, Ciamponi A, Medeiros I, Kanashiro L. Effect of lingual enamel sandblasting with aluminum oxide of different particle sizes in combination with phosphoric acid etching on indirect bonding of lingual brackets. Angle Orthod. 2014;84:1068-73.

27. Suma S, Anita G, Chandra B, Kallury A. The effect of air abrasion on the retention of metallic brackets bonded to fluorosed enamel surface. Indian J Dent Res. 2012;23:230-5.

28. Mati M, Amm E, Bouserhal J, Bassil- Nassif N. Effects of buccal and lingual enamel sandblasting on shear bond strength of orthodontic brackets bonded with a self- etching primer. Int Orthod. 2012; 10:422-31.

29. Halpern R, Rouleau T. The effect of air abrasion preparation on the shear bond strength of an orthodontic bracket bonded to enamel. Eur J Orthod .2010;32:224-7

30. Hantash B, Bedi V, Kapadia B. In vivo histological evaluation of a novel ablative fractional resurfacing device. Lasers Surg Med. 2007;39:96-107.

31. Smith L, Walsh and Taverne A. Removal of Orthodontic Bonding Resin Residues by CO2 Laser Radiation: Surface Effects .Journal of Clinical Laser Medicine \& Surgery. 1999;17:13.

32. Mahshid M, Mohammad B, Nasim C, Zohreh M. Effect of CO2, Nd:YAG and Er:YAG Lasers on Microtensile Bond Strength of Composite to Enamel. The Open Dentistry Journal .2019:13:184-57.

33. Oshagh M, Pakshir H, Najafi H, Naseri M, Nasrabadi $\mathrm{N}$, Torkan S. Comparison of the shear bond strength of orthodontic brackets in bonding and rebonding: preparation with laser versus conventional acid etch technique. Photomed Laser Surg. 2013; 31: 360-4. 
مجلة أسيوط لطب الأسنان
النشر الرسمي لكلية طب الأسنان جامعة الأزهر أسيوط الكاية

مصر

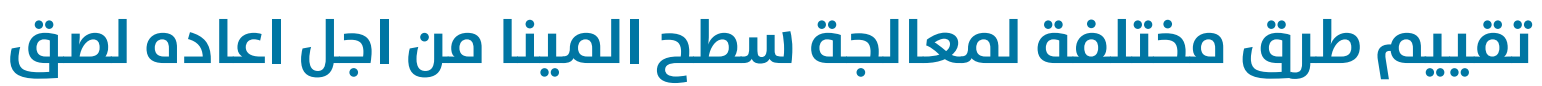

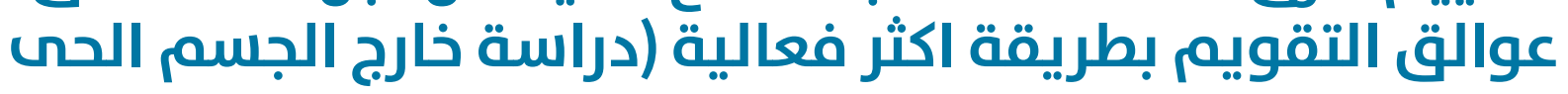

\author{
امال مجدى فضل الكريم1,صالح أنور السيد صالح1, وسام الدين رأفت على جوده1 *, حسن الفكهانى 2 \\ 1. قسـم تقويم الاسـنان، كلية طب الاسـنان ، (بين - اسيوط)، جامعة الأزهر، مصر.

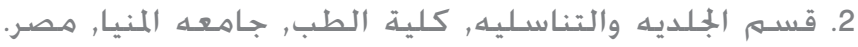

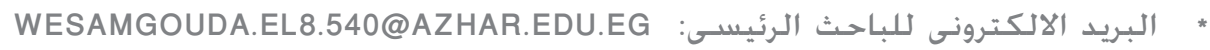

الملخص :

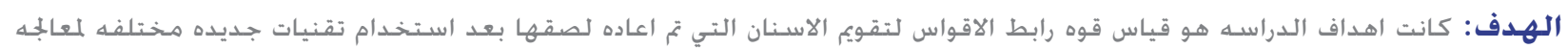

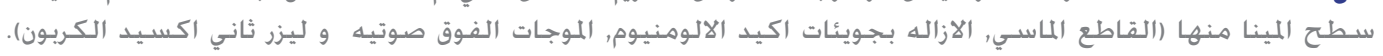

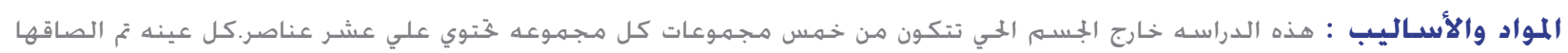

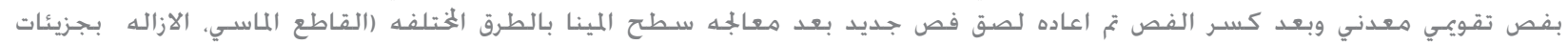

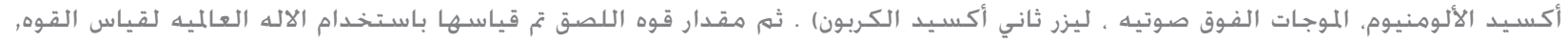

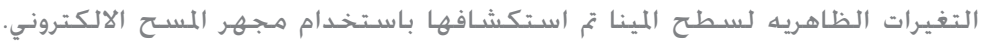

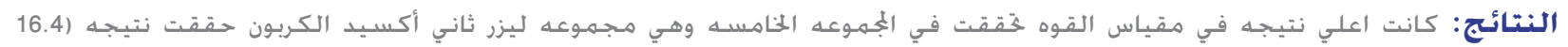

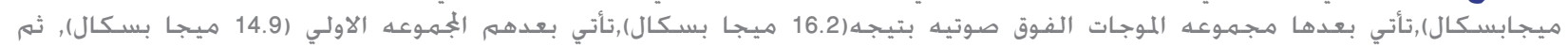

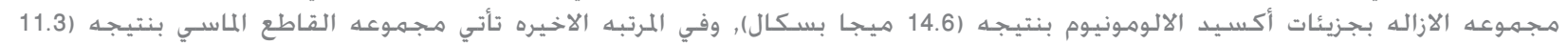

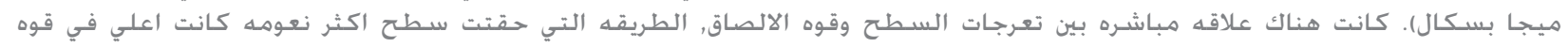
اللصق.

الحنلاصة: كل من الجُموعات السابقه يفضل استخدامها في اعاده لصق عوالق التقويم بدلا من القاطع الماسي وجميعهم حققوا نتائج جيده. الكعلمات المفتاحية: اعاده اللصق ,سطح المينا , اعاده معالجه, ر ابط الاقواس, تقويم الاسنان. 